\title{
FATE OF TUBERCLE BACILLI IN EARLY EXPERIMENTAL INFECTION OF THE MOUSE
}

\author{
BY DAVID F. GRAY* \\ The School of Bacteriology, University of Melbourne, \\ Carlton, N. 3, Victoria, Australia
}

(With Plates 9-11)

\section{INTRODUCTION}

This study was undertaken in an attempt to determine the growth dynamics of tubercle bacilli in the lungs of experimentally infected mice during the first week of the disease.

Previous resports, Raleigh \& Youmans (1948), Stewart (1950), Bloch (1950), Mayer, Jackson, Whiteside \& Alverson (1954), Gray \& Jennings (1955), Gray \& Affleck (1958), and Gray (1958) have produced an acceptable picture of the subsequent course of the disease, but there seems to be no general agreement on the fate of tubercle bacilli during the interval between their initial arrest in the lungs and the end of the first week of infection.

The concept of a variable period of clinical latency formulated by Cohnheim (1881) is fairly generally accepted, but the question to be decided is whether it is a true lag phase or whether bacilli initially observed in the lesion may later be removed. Basing their conclusions on the examination of Ziehl-Neelsen stained sections, Raleigh \& Youmans (1948) suggested that finely dispersed bacilli reaching the lungs from the blood stream were mostly removed from that situation by the defence mechanisms during the first few days, leaving no residue of tissue alteration or reaction. Larger clumps of bacilli were thought more likely to remain in the lung. Following intravenous inoculation of Strong A albino mice with $0.1 \mathrm{mg}$. of virulent tubercle bacilli, these workers reported that acid-fast bacilli were not visible in the lungs or elsewhere, at $24 \mathrm{hr}$., were scarce at $48 \mathrm{hr}$., few in number at 4 and 7 days and were observed in abundance only after 2 weeks.

Using a larger dose to infect albino mice intravenously, viz.: $0.75 \mathrm{mg}$., Stewart (1950) readily found isolated small clumps of tubercle bacilli both at $4 \mathrm{hr}$. and at $24 \mathrm{hr}$. after inoculation, but had difficulty in finding any between the second and seventh days.

In contrast to these reports, Mayer et al. (1954) were able to demonstrate the continuous presence of acid-fast bacilli in the lungs of mice infected intravenously with $0.5 \mathrm{mg}$. of virulent bacilli. They assumed this to be due to their use of an infecting suspension containing many aggregates and relatively few single bacilli.

Dr Mayer, however, who was not satisfied to accept the explanation that bacilli could be washed out of the lung and later replaced, suggested to the present writer

* Aided by grants from the National Health and Medical Research Council, Canberra, A.C.T. 
in 1957 that it might be profitable to examine the lungs by fluorescence microscopy. It had been found previously (Gray, 1953) that this method, by virtue of greater contrast between bacilli and tissues, will reveal acid-fast bacilli in sections that appear to be negative when stained by the Ziehl-Neelsen method. It also possesses the advantage that the decolorization time can be reduced to as little as $2 \mathrm{~min}$. to detect possible variations in acid fastness. As the problem had also been discussed previously with Dr Youmans without reaching a satisfactory solution, the following study was undertaken.

Known numbers of tubercle bacilli, of which the state of dispersion was carefully checked, were used to infect two different strains of mice intranasally and intravenously. Lungs were examined after $2 \mathrm{hr}$. and subsequently at intervals of $24 \mathrm{hr}$. for at least 7 days. Sections of the lungs were compared using fluorescence and Ziehl-Neelsen staining and the distribution of single cells and clumps noted. As a quantitative approach appeared most likely to indicate whether the phenomenon was one involving a lag phase or removal of bacilli, other lungs were homogenized and serial dilutions examined for their content of culturable and stainable bacilli.

\section{MATERIALS AND METHODS}

Bacterial cultures and suspensions used for infection studies. The virulent human strain, H37Rv, kept in the dried state after animal passage, was subcultured several times in Dubos and Davis Tween-albumin medium (1946) to obtain a uniformly good dispersal of organisms. Prior to use, cultures were further dispersed by treatment for $5 \mathrm{~min}$. at 14,000 r.p.m. in square-bottomed glass containers of $25 \mathrm{ml}$. capacity on an M.S.E. Micro Homogenizer.* The same apparatus fitted with containers of $3 \mathrm{ml}$. capacity was used for homogenizing mouse lungs.

Homogenized cultures were lightly centrifuged for 3 min. at 1000 r.p.m. The supernatant fluid was then filtered twice through cotton-wool by the simple expedient of dropping a wisp of sterile wool into the suspension, pushing this into a compact mass at the bottom of the container with a Pasteur pipette and then sucking the organisms through the packed wool into the pipette with the aid of a rubber teat.

Smears of the suspensions were examined by fluorescence microscopy to determine the degree of dispersion (see Pl. 9, fig. 1).

Mouse strains. C57 Black mice introduced from the Roscoe Jackson Memorial Laboratories in 1947 and since bred as a pure line, were compared with Melbourne University albino mice (MUA). The mice were 8 weeks old at the time of infection and were maintained on an adequate cereal diet with vitamin supplement.

Methods of inoculation. Intranasal inoculation consisted of introducing $0.06 \mathrm{ml}$. of inoculum on to the nostrils of mice anaesthetized with a mixture of 2 parts of ether to 1 part of chloroform. With cough, sneeze and swallowing reflexes inhibited, the inoculum is inhaled evenly and completely into the lungs. India ink so inoculated produces uniform grey discoloration of the entire lung tissue. Intravenous inoculation consisted of introducing $0.5 \mathrm{ml}$. volumes into a tail vein.

\footnotetext{
* Thomas Optical and Scientific Co., Melbourne, Victoria.
} 
Protection of laboratory personnel. Many workers in this field have queried the safety of inoculating virulent tubercle bacilli intranasally. This method is considered to be free of risk to the operator and attendants if normal precautions are adopted, as is necessary in all manipulations with virulent tubercle bacilli. Although it has been in continuous use in these laboratories for 10 years, no case of tuberculosis has been detected in the staff during that period.

The following routine precautions are observed: Mantoux negative newcomers are given B.C.G. and all personnel are examined radiologically every 12 months. Masks are worn during manipulations involving living bacilli or infected animals, which are performed in bacteriological hoods under negative pressure and ultraviolet irradiation.

After intranasal inoculation mice or guinea-pigs remain under the hood for at least $\mathrm{l} \mathrm{hr}$. to minimize the risk of returning bacilli to the air and are subsequently housed in an isolation unit. This area is continuously under ultraviolet irradiation except when occupied by workers. Ethyl alcohol in $70 \%$ aqueous solution is used freely. To this is added 1/1000 Zephiran for hand decontamination. Both of these preparations have been shown to kill tubercle bacilli in sputum within $2 \mathrm{~min}$.

Lung examination. Mice were sacrificed by exposure to coal gas at the appropriate intervals and the lungs removed aseptically. Some were fixed in $10 \%$ formalin and the rest homogenized individually in the M.S.E. Micro-Homogenizer with $2 \mathrm{ml}$. of $0.1 \%$ albumin water.* After 5 min. grinding the volume was made up to $10 \mathrm{ml}$., giving a $10^{-1}$ dilution of lung and further tenfold serial dilutions were then made in $0 \cdot 1 \%$ albumin water. Counts were made by transferring dilutions with a dropping pipette (Pasteur pipette calibrated to approximately 50 drops per ml.) on to cleaned microscope slides (Affleck \& Gray, 1957) and on to Löwenstein's medium. Sixfold stainable counts and culturable counts were made on each dilution.

Stainable counts. The drop smears each represented $0.02 \mathrm{ml}$. of the corresponding dilution of lung suspension. These were fixed on a hot plate at $75-85^{\circ} \mathrm{C}$. and stained at this temperature for $10 \mathrm{~min}$. with auramine-rhodamine complex (Gray, 1953). Excess stain was poured off, the slide washed very gently in water and immersed in $1 \%$ acid alcohol $\dagger$ for exactly $2 \mathrm{~min}$. [N.B. This time is shorter than is normally employed and is significant in relation to the degree of acid fastness of the bacilli (see Results).]

After a further very gentle immersion and soaking in water to remove acid, the slide was drained and dried in a vertical position in a current of warm air.

Counting technique. The apparatus for microscopy was that described previously (Gray, 1953) with minor modifications to facilitate counting the bacilli in the drop smears.

Into the eyepiece above the G15 Kodak Wratten gelatin filter, was inserted a manilla paper disk cut out to give a rectangular, instead of the usual round field with its poor peripheral focus. The optical system was a K 10 compensating

* Bovine Albumin fraction V (Armour) in distilled water.

$\dagger 1 \% \mathrm{HCl}$ in $70 \%$ aqueous ethyl alcohol $(\mathrm{v} / \mathrm{v})$. 
eyepiece and a $\times 20,0 \cdot 65$ N.A. objective combining to give a relatively flat field at a magnification of $\times 200$. A coverslip was dropped on to the top of the slide because this objective is not corrected for use without one, and liquid paraffin was placed between the condenser and the slide. Adjustment of condenser height and centring the light were both critical in revealing all the bacilli in the preparation. A mechanical tally counter was used to count the whole of the drop smear. Almost all the bacilli were found to be arranged singly (Affleck \& Gray, 1957), but small clumps, when they did occur, were counted as one unit so that a comparison of colony counts with stainable bacilli was possible at any given dilution (see Tables 1 and 2).

Culturable counts were based on the average of two drops of each dilution on to each of three Löwenstein slopes put up in screw-capped McCartney bottles (six drops per dilution). Before the inoculation was carried out an antibiotic mixture was rinsed over the surface of each slope and the surplus immediately discarded. The antibiotic mixture, consisting of 10 units of penicillin and $10 \mu \mathrm{g}$. of chloramphenicol per ml., was used to combat occasional lung contaminants, as previous experience had shown that this procedure did not affect appreciably the count of tubercle bacilli. Colonies were counted after 3 weeks' incubation at $37^{\circ} \mathrm{C}$.

Sections. The entire bronchial tree was fixed in $10 \%$ formalin and sectioned transversely through its widest diameter to take in the majority of the lobes. The lungs of three mice, sacrificed at each interval, were embedded in the same block and the results described are the average for the group in each case. For technical reasons the plates $(\mathrm{Pl} .9$, figs. 2,3 ; Pls. 10,11)* represent the heaviest concentrations of bacilli detected at each period of the test rather than the overall appearance of the lungs.

\section{RESULTS}

\section{Intranasal inoculation}

Although previous workers had used the intravenous method of inoculation it was decided to infect mice intranasally in the first place for several reasons. Extensive previous experience with this method indicated that known numbers of bacilli could be introduced directly into the lungs in this manner. Moreover, small numbers of bacilli reaching the lungs could be expected to produce approximately corresponding numbers of tubercles. The intravenous method, on the other hand, was known to be a less efficient means of obtaining a predictable number of tubercles in the lungs (Gray \& Mattinson, 1952). The actual portal of entry seemed relatively unimportant for, if the apparent removal of bacilli took place between the 4th and 48th hour (Raleigh \& Youmans (1948) and Stewart (1950)) then it would be by phagocytosis from the tissues rather than from the blood vessels or the alveoli (Mayer et al. 1954).

Ten-day cultures of strain $\mathrm{H} 37 \mathrm{Rv}$ in Tween-albumin medium were homogenized for $5 \mathrm{~min}$., lightly centrifuged and filtered through cotton-wool. Smears of the

* The photographs were taken with a Contax camera on Ilford Pan F film with a $\mathrm{K} 10$ compensating eyepiece and $a \times 20,6.5 \mathrm{~N} . \mathrm{A}$. objective. Using a $12 \mathrm{~V} .100 \mathrm{~W}$. projection globe, the average exposure time was $2 \frac{1}{2} \mathrm{~min}$. 
resulting suspension were found to consist principally of single cells, but with a few clumps of five to ten bacilli per high power field (Pl. 9, fig. 1).

Sixty $\mathrm{C} 57$ black mice and the same number of MUA mice 8-9 weeks old were infected intranasally with $0.06 \mathrm{ml}$. of a $10^{-1}$ dilution of the above, which was found to contain approx. 700,000 culturable units and stainable units per mouse dose. Two hours later and subsequently at $24 \mathrm{hr}$. intervals, six mice in each group were killed, three for section and three for bacillary counts. The results are presented in Tables 1 and 2.

Table 1. Counts of stainable and culturable tubercle bacilli in the lungs of C57 black mice infected intranasally with 700,000 bacillary units (stainable count 690,000, culturable count 710,000 )

\begin{tabular}{|c|c|c|c|c|c|c|}
\hline \multirow[b]{2}{*}{$\begin{array}{l}\text { Mouse } \\
\text { no. }\end{array}$} & \multirow[b]{2}{*}{$\begin{array}{c}\text { Days } \\
\text { since } \\
\text { infection }\end{array}$} & \multicolumn{2}{|c|}{$\begin{array}{l}\text { Count of stainable } \\
\text { bacillary units } \\
\text { at } 10^{-4} \text { dilution* }\end{array}$} & \multicolumn{2}{|c|}{$\begin{array}{c}\text { Count of eulturable } \\
\text { colonies at } \\
10^{-4} \text { dilution } \dagger\end{array}$} & \multirow{2}{*}{$\begin{array}{c}\text { Ratio of } \\
\text { stainable/ } \\
\text { culturable } \\
\text { counts. } \\
\text { Daily } \\
\text { average }\end{array}$} \\
\hline & & $\begin{array}{l}\text { Individual } \\
\text { mice }\end{array}$ & $\begin{array}{c}\text { Daily } \\
\text { average }\end{array}$ & $\begin{array}{l}\text { Individual } \\
\text { mice }\end{array}$ & $\begin{array}{l}\text { Daily } \\
\text { average }\end{array}$ & \\
\hline $\begin{array}{l}1 \\
2 \\
3\end{array}$ & $0(2 \mathrm{hr})$. & $\left.\begin{array}{l}1 \cdot 8 \\
2 \cdot 4 \\
1.9\end{array}\right\}$ & 2 & \begin{tabular}{l|l}
$c$ \\
$c$ \\
$c$
\end{tabular} & - & - \\
\hline $\begin{array}{l}4 \\
5 \\
6\end{array}$ & 1 & $\left.\begin{array}{l}9 \cdot 6 \\
3 \cdot 7 \\
9\end{array}\right\}$ & $7 \cdot 4$ & $\begin{array}{r}7 \\
15 \\
8\end{array}$ & 10 & $1: 1 \cdot 4$ \\
\hline $\begin{array}{l}7 \\
8 \\
9\end{array}$ & 2 & $\left.\begin{array}{r}19 \cdot 3 \\
11 \cdot 3 \\
8 \cdot 3\end{array}\right\}$ & 13 & $\begin{array}{r}9 \\
8 \\
10\end{array}$ & 9 & $1.5: 1$ \\
\hline $\begin{array}{l}10 \\
11 \\
12\end{array}$ & 3 & $\left.\begin{array}{c}9 \cdot 6 \\
8 \\
10\end{array}\right\}$ & $9 \cdot 2$ & $\left.\begin{array}{l}8 \cdot 5 \\
5 \cdot 5 \\
9\end{array}\right\}$ & $7 \cdot 6$ & $1 \cdot 2: 1$ \\
\hline $\begin{array}{l}13 \\
14 \\
15\end{array}$ & 4 & $\left.\begin{array}{r}8 \\
22 \\
14\end{array}\right\}$ & $14 \cdot 5$ & $\left.\begin{array}{l}5 \\
9 \cdot 8 \\
7\end{array}\right\}$ & 7 & $2 \cdot 1: 1$ \\
\hline $\begin{array}{l}16 \\
17 \\
18\end{array}$ & 5 & $\left.\begin{array}{l}34 \\
12 \\
19 \cdot 3\end{array}\right\}$ & 22 & $\left.\begin{array}{l}8 \cdot 5 \\
12 \cdot 25 \\
10 \cdot 5\end{array}\right\}$ & 10.5 & $2: 1$ \\
\hline $\begin{array}{l}19 \\
20 \\
21\end{array}$ & 6 & $\begin{array}{l}41 \\
17 \\
31\end{array} \mid$ & 30 & $\left.\begin{array}{l}26 \\
17 \\
10\end{array}\right\}$ & $17 \cdot 7$ & $1 \cdot 7: 1$ \\
\hline $\begin{array}{l}22 \\
23 \\
24\end{array}$ & 7 & $\left.\begin{array}{l}16 \\
19 \\
50\end{array}\right\}$ & 28 & $\left.\begin{array}{l}21 \\
10 \\
32\end{array}\right\}$ & 21 & $1 \cdot 3: 1$ \\
\hline $\begin{array}{l}25 \\
26 \\
27\end{array}$ & 8 & $\left.\begin{array}{r}116 \\
34 \\
75\end{array}\right\}$ & 75 & $\begin{array}{l}50 \\
34 \\
42\end{array}$ & 42 & $1 \cdot 8: 1$ \\
\hline
\end{tabular}

* This figure is the average of 6 counts on $0.02 \mathrm{ml}$. drop smears, examined by fluorescence microscopy. Multiplied, $\times 50 \times 10^{4}$, it gives the total number of bacillary units in the whole lung.

+ This is the average number of colonies from 6 drops of the appropriate dilution on Löwenstein's medium after 3 weeks at $37^{\circ} \mathrm{C}$. The above calculation applies for the whole lung. $\mathrm{c}=$ Cultures contaminated. 
Table 2. Counts of stainable and culturable tubercle bacilli in the lungs of MUA mice infected intranasally with 700,000 bacillary units

\begin{tabular}{|c|c|c|c|c|c|c|}
\hline \multirow[b]{2}{*}{$\begin{array}{l}\text { Mouse } \\
\text { no. }\end{array}$} & \multirow[b]{2}{*}{$\begin{array}{l}\text { Days } \\
\text { since } \\
\text { infection }\end{array}$} & \multicolumn{2}{|c|}{$\begin{array}{l}\text { Count of stainable } \\
\text { bacillary units } \\
\text { at } 10^{-4} \text { dilution }\end{array}$} & \multicolumn{2}{|c|}{$\begin{array}{c}\text { Count of culturable } \\
\text { colonies at } 10^{-4} \\
\text { dilution }\end{array}$} & \multirow{2}{*}{$\begin{array}{c}\text { Ratio of } \\
\text { stainable/ } \\
\text { culturable } \\
\text { counts. } \\
\text { Daily } \\
\text { average }\end{array}$} \\
\hline & & $\begin{array}{c}\text { Individual } \\
\text { mice }\end{array}$ & $\begin{array}{c}\text { Daily } \\
\text { average }\end{array}$ & $\begin{array}{l}\text { Individual } \\
\text { mice }\end{array}$ & $\begin{array}{c}\text { Daily } \\
\text { average }\end{array}$ & \\
\hline $\begin{array}{l}\mathbf{1} \\
\mathbf{2} \\
\mathbf{3}\end{array}$ & 0 & $\left.\begin{array}{l}1 \cdot 6 \\
1 \cdot 5 \\
1 \cdot 5\end{array}\right\}$ & $1 \cdot 5$ & $\left.\begin{array}{l}\mathrm{c} \\
\mathrm{c}\end{array}\right\}$ & - & - \\
\hline $\begin{array}{l}4 \\
5 \\
6\end{array}$ & 1 & $\left.\begin{array}{r}12 \\
8 \\
12\end{array}\right\}$ & $10 \cdot 6$ & $\left.\begin{array}{l}8 \\
7 \\
8\end{array}\right\}$ & $7 \cdot 6$ & $1 \cdot 4: 1$ \\
\hline $\begin{array}{l}7 \\
8 \\
9\end{array}$ & 2 & $\left.\begin{array}{c}12 \cdot 6 \\
6 \\
4\end{array}\right\}$ & $7 \cdot 5$ & $\left.\begin{array}{r}14 \\
7 \\
5\end{array}\right\}$ & $8 \cdot 6$ & $1: 1 \cdot 1$ \\
\hline $\begin{array}{l}10 \\
11 \\
12\end{array}$ & 3 & $\left.\begin{array}{l}15 \\
14 \\
12 \cdot 6\end{array}\right\}$ & 14 & $\left.\begin{array}{r}c \\
12 \\
c\end{array}\right\}$ & 12 & $1: 1 \cdot 1$ \\
\hline $\begin{array}{l}13 \\
14 \\
15\end{array}$ & 4 & $\left.\begin{array}{r}7 \\
20 \\
24\end{array}\right\}$ & 17 & $\left.\begin{array}{c}8 \cdot 5 \\
18 \\
21\end{array}\right\}$ & 16 & $1: 1$ \\
\hline $\begin{array}{l}16 \\
17 \\
18\end{array}$ & 5 & $\left.\begin{array}{l}15 \\
48 \\
17\end{array}\right\}$ & 27 & $\left.\begin{array}{l}20 \\
50 \\
21\end{array}\right\}$ & 30 & $1: 1 \cdot 1$ \\
\hline $\begin{array}{l}19 \\
20 \\
21\end{array}$ & 6 & $\left.\begin{array}{l}14 \\
19 \\
13\end{array}\right\}$ & 24 & $\left.\begin{array}{l}52 \\
25 \\
12\end{array}\right\}$ & 30 & $1: 1 \cdot 2$ \\
\hline $\begin{array}{l}22 \\
23 \\
24\end{array}$ & 7 & $\left.\begin{array}{r}28 \\
14 \\
103\end{array}\right\}$ & 48 & $\left.\begin{array}{l}20 \\
14 \\
90\end{array}\right\}$ & 41 & $1 \cdot 2: 1$ \\
\hline
\end{tabular}

See Table 1 for conditions governing these counts. These mice were infected at the same time and with the same inoculum as the $\mathrm{C} 57$ black mice.

The purpose of the experiment being to compare stainable with culturable bacilli, the results have been shown respectively as bacillary units or colonies detected in $0.02 \mathrm{ml}$. of a given dilution throughout the test period. The zero time figures were transposed from counts at $10^{-3}$ dilution to simplify the presentation. It is noteworthy that the same close relationship of stainable to culturable bacilli observed previously in mouse lung suspensions (Affleck \& Gray, 1957) was again evident. Within the limits of error imposed by the techniques employed, most of the visible bacilli appeared to be viable and vice versa, and the two different strains of mice appeared to respond to infection in a remarkably similar fashion. In a later report it is proposed to relate this observation to the variable resistance of different mouse strains to experimental tuberculosis.

The over-all picture obtained was that of an apparent initial increase in culturable bacillary numbers during the first day, followed by a quiescent phase or one of minimal multiplication lasting until the third or fourth day. There was nothing to 
suggest that removal of any considerable numbers of bacilli from the lungs occurred at any stage. Only after the fifth or sixth day was continuous multiplication detected. (See also Gray \& Jennings, 1955; and Gray \& Affleck, 1958.)

The distribution of stainable bacilli, as judged by a study of the sections stained by auramine-rhodamine, agreed well with the cultural findings (see PI. 9, figs. 2, 3; Pls. 10, 11). Bearing in mind the relative infrequency of clumps in the inoculum it was surprising to find that aggregates of from 10 to 20 bacilli were common throughout the $2 \mathrm{hr}$. sections, while relatively small numbers of single bacilli were to be seen (Pl. 9, fig. 2). These clumps were located in the interalveolar septa, apparently having passed rapidly from the alveoli into the tissues. As cell structure is not readily seen under fluorescence, it cannot be certain that the clumps observed were located within phagocytes, but it seems highly probable (Mayer et al. 1954) that this was the case. It is presumed that the well dispersed bacilli making up the inoculum (Pl. 9, fig. 1) were aggregated, either in the lace-like mucous network lining the alveoli or by actively scavenging macrophages, and penetrated into the alveolar walls in clumps rather than singly.

Subsequent events in the dynamics of the bacillary population were similar to those so adequately described by Mayer and his co-workers (1954). The bacillary clumps were quickly broken up and dispersed (Pl. 9, fig. 3) so that clumping was unusual from the second to the fourth day. The predominance of single cells or of static small clumps scattered through the exudate rather than clusters during this period is in accordance with the lag in bacillary multiplication shown in Tables 1 and 2. Conversely, the onset of rapid bacillary multiplication at the fifth or sixth day is reflected in the wider distribution, as well as in the increasing number and size of aggregates observed, at this stage.

In adjacent sections to the above, stained with Ziehl-Neelsen and decolorized for the usual period of 10-15 min., acid-fast bacilli were readily found up to $24 \mathrm{hr}$. after infection and from the sixth day onwards. In sections representing the second to fifth days they were found after a careful search. The bacilli tended to be scattered and it was noted that a considerable proportion of those seen were lightly stained. This apparent reduction in acid fastness suggested that it would be profitable to prolong the decolorization period in the fluorescence method to $10 \mathrm{~min}$. in place of the $2 \mathrm{~min}$. used in the observations already described. When this was done, it was found that from 30 to $50 \%$ of bacilli in lung sections or drop-smears from the second to the fifth day stained yellow or lemon colour instead of the usual red-gold, indicating a reduced ability to hold the dye. On the other hand, weakly acid-fast forms were rarely seen in the inoculum, or in tissues from the very early or later stages of the infection.

\section{Intravenous inoculation}

It is believed, as has already been intimated, that the only essential differences between intranasal and intravenous inoculation are in the pathway of penetration of the bacilli into the alveolar walls during the first hour to two, and in the greater efficiency of the former method in getting a predictable number of bacilli into the lungs. Nevertheless, as the observations that led to the 'eclipse phase' theory were 
made on mice infected intravenously, this method of inoculation was subjected to the same scrutiny as the intranasal method already described. An attempt was made in this experiment to eliminate all clumps from the suspension, in order to give the eclipse phenomenon every chance of manifesting itself. Homogenization for $10 \mathrm{~min}$., light centrifugation for $10 \mathrm{~min}$. and three filtrations through cottonwool produced a suspension consisting almost entirely of single cells as far as could be ascertained by searching stained smears.

Table 3. Counts of stainable and culturable tubercle bacilli in the lungs of $M U A$ mice infected intravenously with 1,150,000 bacillary units, finely dispersed

$\begin{array}{ccc}\begin{array}{c}\text { Days since } \\ \text { infection }\end{array} & \overbrace{\text { By staining }}^{\text {No. of bacillary units per lung }} \\ 0 & 35,000 & \text { By culture } \\ 1 & 30,000 & 20,000 \\ 2 & 40,000 & 30,000 \\ 3 & 20,000 & 27,500 \\ 4 & 40,000 & 15,000 \\ 5 & 30,000 & 27,500 \\ 6 & 25,000 & \text { Contam. } \\ 7 & 75,000 & 27,500 \\ 8 & - & 45,000 \\ & & 46,500\end{array}$

See Table 1 for conditions governing these counts.

The infecting dose, $0.5 \mathrm{ml}$. of this suspension, was found to contain approximately $1.15 \times 10^{6}$ bacillary units both by staining and by culture. Infected MUA mice were killed at the appropriate intervals to provide material for sections and for counts. The comparative stainable and culturable counts are to be seen in Table 3. It seems that only about $3 \%$ of the inoculated bacilli lodged in the lungs, and it is believed that a good deal of variation occurred in the number of bacilli retained in the lungs by different animals. This was in striking contrast to the situation in the intranasally inoculated group and may have been accentuated by the very fine state of dispersion of the inoculum. It meant that the initial lung population of bacilli did not exceed one-twentieth that of the intranasal group and that over one million bacilli were located elsewhere in the body. Nevertheless, the picture obtained was similar to that described above.

Sections stained for fluorescence microscopy showed the same initial clumping, followed by dispersion lasting up to the sixth day. From the seventh day onwards groups of multiplying bacilli appeared. When decolorization with acid alcohol was prolonged, the same proportional decrease in acid fastness was observed in the middle period.

Thus, there is no reason to suppose that the course of the first week of infection was influenced appreciably by the route of inoculation employed. The sequence of events would appear to have been this:

(1) Bacilli entering the lungs passed rapidly into the alveolar tissue from the blood vessels or the alveoli, depending on the portal of entry. There was a tendency 
for finely dispersed bacilli to be aggregated into clumps in the process, though many single bacilli could also be seen in the tissues.

(2) These clumps, together with clumps that lodged in the lungs as such, were broken up after $24 \mathrm{hr}$. and remained for several days as scattered single bacilli or static tiny clumps widely dispersed through the increasing area of pneumonia surrounding the initial focus of infection.

(3) That little multiplication occurred in the first 4 or 5 days is suggested by the observed predominance of isolated single cells or static small clumps.

(4) During this period many of the bacilli were readily decolorized, either partly or completely, by acid alcohol. The detection of widely scattered bacilli of reduced acid fastness was difficult with Ziehl-Neelsen staining, but their presence could readily be demonstrated by fluorescence microscopy, particularly if the decolorization time with acid alcohol was restricted to $2 \mathrm{~min}$.

(5) The lag phase gave way to one of rapid multiplication of bacilli on the fifth or sixth day and these rapidly growing bacilli then appeared in dense masses that were predominantly strongly acid fast.

\section{DISCUSSION}

In seeking an explanation of the apparent anomaly between the findings of earlier workers and those of Mayer and his colleagues and of the present writer, it must be remembered that only in the current series were morphological findings compared with the numbers of culturable bacilli in the lungs. Here, also, a highly contrasting staining method was employed, one that will probably reveal all the acid-fast bacilli in infected material.

A probable explanation of early failures to demonstrate the continuous presence of the anticipated numbers of tubercle bacilli in the lungs of experimental mice lies in the temporarily suspended multiplication and in the concurrent wide scattering of bacilli through the exudate, often in a state of reduced acid fastness.

It will be observed (Tables 1 and 2) that there was apparently a steep rise in stainable bacilli between the second and twenty-fourth hour after intranasal infection. Unfortunately, the $2 \mathrm{hr}$. figure cannot be confirmed by the corresponding culturable count, which was contaminated, but indirect confirmation comes from the known size of the infecting dose. As this rise was not observed when the finely dispersed culture was inoculated intravenously (Table 3), it is concluded that cohesive clumps in the original inoculum that were each counted as one bacillary unit, were subsequently dispersed by phagocytic action in the lung to give an increased count after $24 \mathrm{hr}$. It seems reasonable in view of later events, to assume that multiplication of bacilli, both before and during the observed lag phase, was reduced to a minimum.

No explanation is offered for the lag phase and its later transition to one of rapid and continuous multiplication. The lag phase appears to be one in which the bacillus becomes adjusted to an intracellular existence, with restricted multiplication and a temporary reduction in acid fastness as two of its manifestations. During a visit to his laboratories, in 1956, Dr E. M. Brieger produced for me some 
impressive evidence of a temporary loss of acid fastness when tubercle bacilli were grown in tissue cultures derived from an animal species for which the bacilli were pathogenic. This did not occur when the cells were derived from an animal for which the bacilli were not pathogenic (e.g. avian cells infected with mammalian bacilli). It is conceivable that a similar phenomenon was involved in the present experiments.

With regard to the numbers of bacilli detected from day to day, it is noteworthy that the growth dynamics of tubercle bacilli in isolated monocytes are not dissimilar from those observed in the lungs of mice in the present studies. Reference to the results of Mackaness, Smith \& Wells (1953) shows that virulent bacilli within normal monocytes in tissue culture multiply slowly up to the 5th day and rapidly thereafter. Moreover, these workers concluded that even protracted lag periods result from failure to grow and not from coincident multiplication and destruction of bacilli. There is therefore, every reason to suppose that the results reported here relate to lag followed by multiplication and not to the supposed removal or destruction of single bacilli lodged initially in the lung and their later replacement by the multiplication of clumps surviving the onslaught of the defence mechanisms. The ability of monocytes to inhibit and destroy tubercle bacilli actually appears to emerge later in the disease process.

\section{SUMMARY}

1. The question of a possible eclipse phase during the first week of experimental mouse tuberculosis has been examined.

2. Using fluorescence microscopy to examine sections and to perform counts of stainable bacilli for comparison with counts of culturable bacilli in the lungs it was found that bacilli multiplied very slowly during the first 5 days, and rapidly from about the sixth day onwards.

3. At all times there was close agreement between stainable and culturable bacilli in the lungs.

4. During the lag phase, the bacilli occurred as widely scattered, often weakly acid-fast cells that were difficult to detect by Ziehl-Neelsen staining.

5. Active removal of bacilli by phagocytes is believed not to be important at this stage.

6. After 5 or 6 days, clusters of bacilli, rapidly increasing in number and size and strongly acid fast, were readily detected in the lungs.

\section{REFERENCES}

AfFleck, M. N. \& GRAY, D. F. (1957). Viable and stainable counts on tubercle bacilli in tuberculous tissue. Amer. Rev. Tuberc. 75, 519.

BLOCH, H. (1950). Studies on the virulence of tubercle bacilli. The relationship of the physiological state of the organisms to their pathogenicity. J. exp. Med. 92, 507.

CöNHErm, J. (1881). Die tuberkulose vom standpunkte infektionslehre. Leipsig.

Duros, R. J. \& Davis, B. D. (1946). Factors affecting the growth of tubercle bacilli in liquid media. J. exp. Med. 83, 409.

GraY, D. F. (1953). Detection of small numbers of mycobacteria in sections by fluorescence microscopy. Amer. Rev. Tuberc. 68, 82. 

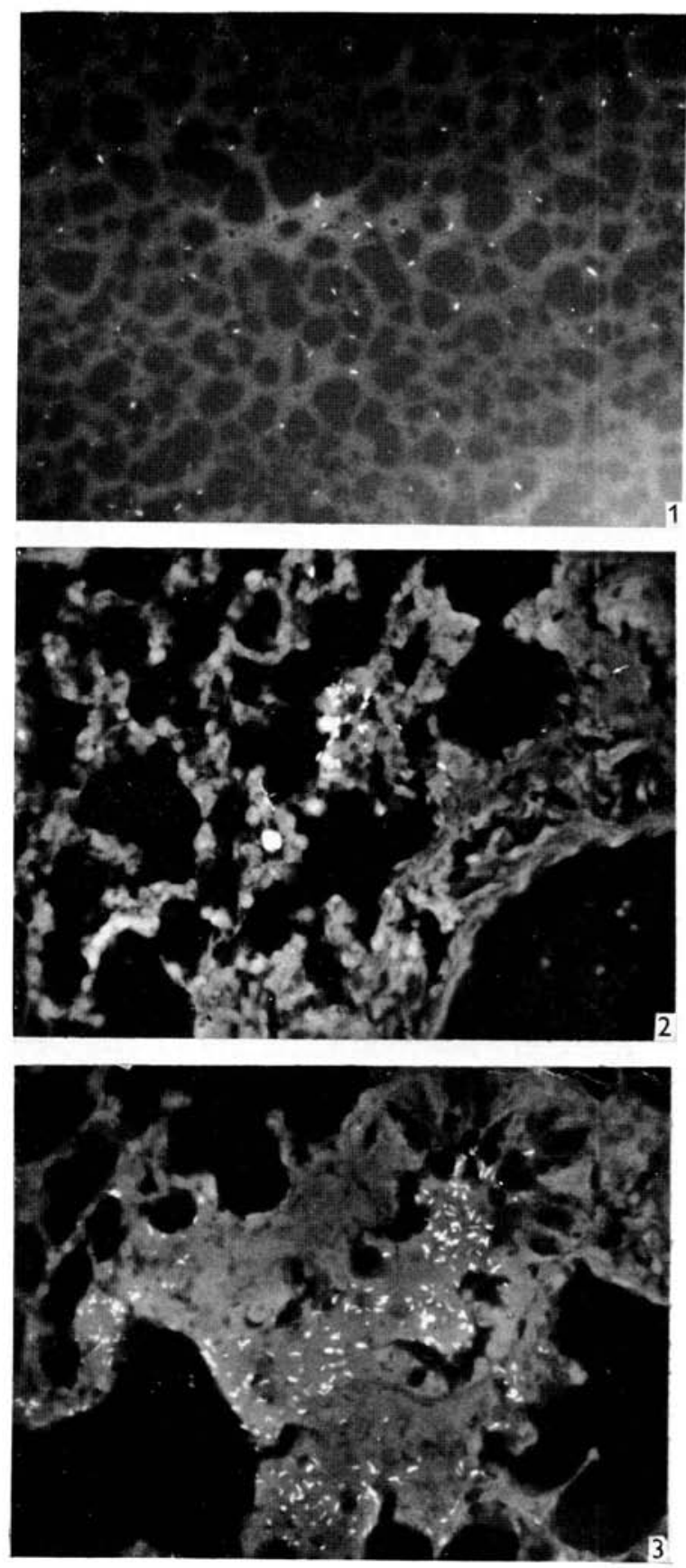

(Facing p. 482) 

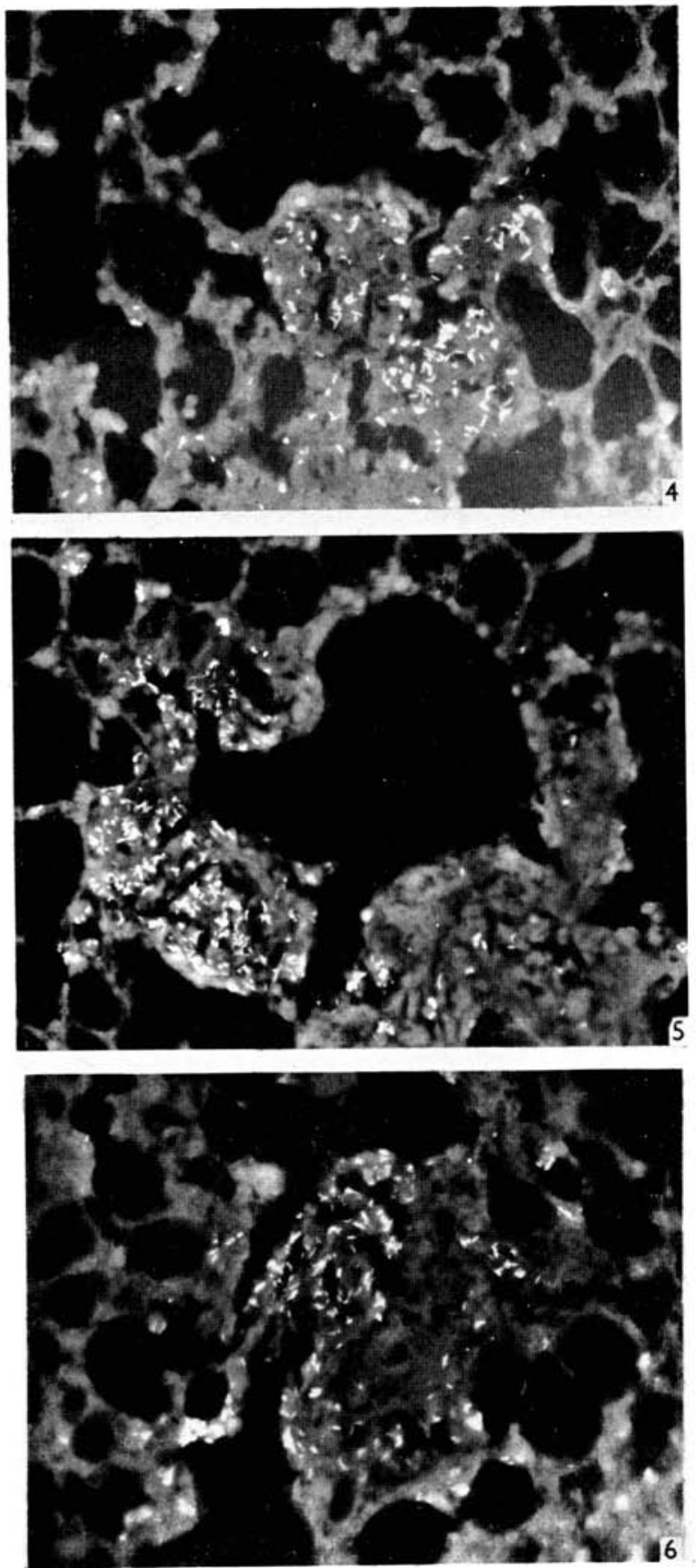

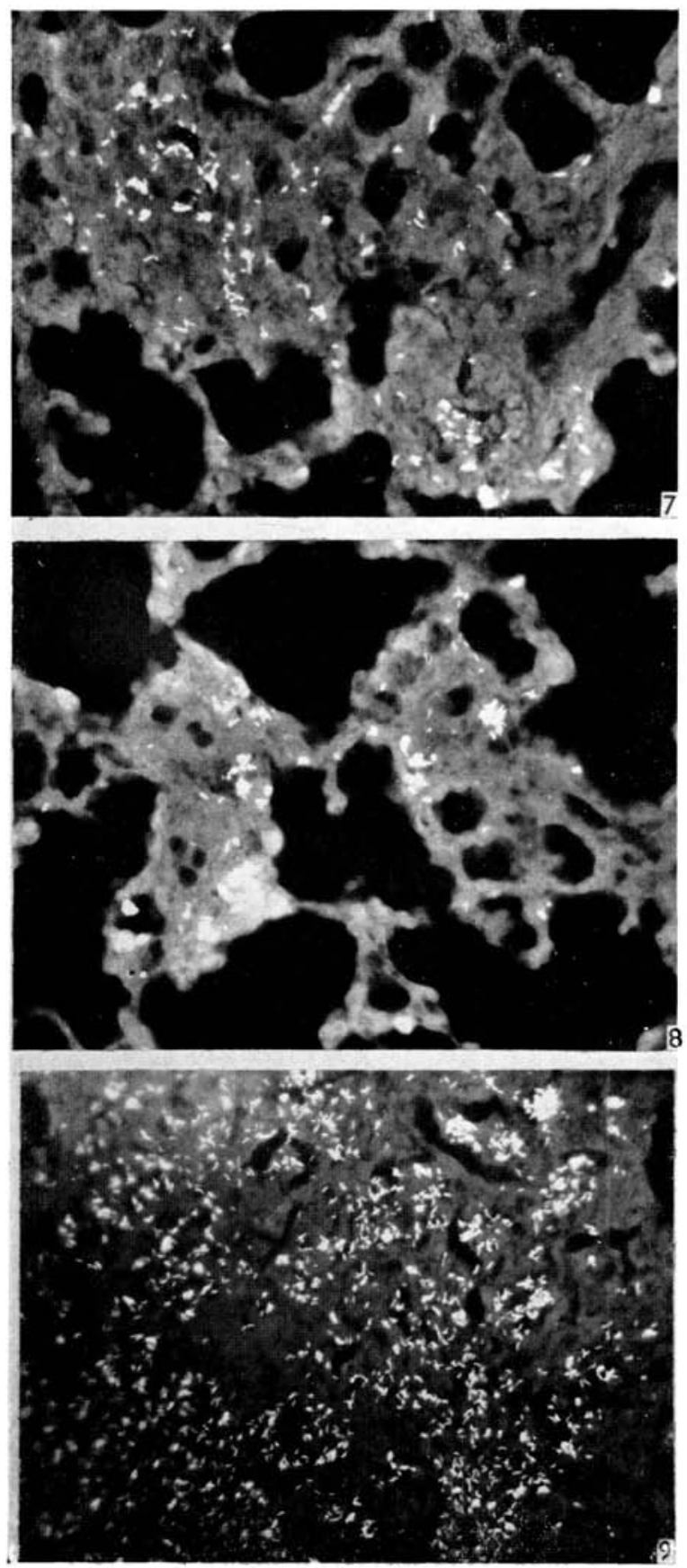
GRAY, D. F. (1958). Immunity, natural allergy and artificial desensitization in experimental tuberculosis. Amer. Rev. Tuberc. 78, 235.

Gray, D. F. \& AFrLeor, M. N. (1958). Relationship of allergy to gross lung disease and culturable bacilli in tuberculous mice. Amer. Rev. Tuberc. 78, 226.

Gray, D. F. \& Jennings, P. A. (1955). Allergy in experimental mouse tuberculosis. Amer. Rev. Tuberc. 72, 171.

Gray, D. F. \& Mattinson, M. W. (1952). Detection of small numbers of tubercle bacilli from dispersed cultures, using mice, guinea pigs and artificial media. Amer. Rev. Tuberc. $65,572$.

Mackaness, G. B., Smith, N. \& Welds, A. Q. (1953). The growth of intracellular tubercle bacilli in relation to their virulence. Amer. Rev. Tuberc. 69, 479.

Mayer, E., Jackson, E. R., Whiteside, E. S. \& Alverson, C. (1954). Experimental embolic pulmonary tuberculosis in mice. Amer. Rev. Tuberc. 69, 419.

Rateigh, G. W. \& Youmans, G. P. (1948). The use of mice in experimental chemotherapy of tuberculosis. II. Pathology and pathogenesis. J. infect. Dis. 82, 205.

STEWART, G. T. (1950). The pathogenesis of tuberculosis in mice infected intravenously with human tubercle bacilli; the use of mice in chemotherapeutic tests. Brit. J. exp. Path. 31,5 .

\section{EXPLANATION OF PLATES 9-11 \\ Plate 9}

Distribution of tubercle bacilli in the lungs of mice during the first seven days of infection. Auramine-Rhodamine stain for Fluorescence Microscopy. All figures $\times 450$.

Fig. 1. Inoculum suspended in albumin water showing mainly single bacilli, with occasional clumps of 5-10 organisms.

Fig. 2. Two hours. Scattered bacilli of inoculum gathered into clumps of 5-50 bacilli in alveolar walls. Single bacilli rarely seen.

Fig. 3. Clumps dispersed; mainly single cells or tiny clusters scattered widely through the increasing area of pneumonia.

\section{Plate 10}

Fig. 4. Two days. Little change.

Fig. 5. Three days. Little change.

Fig. 6. Four days. Little change. Clusters of bacilli enlarging.

\section{Plate 11}

Fig. 7. Five days. Clusters increasing in number. Pneumonic areas extending.

Fig. 8. Six days. Clusters increasing in size-single bacilli rare.

Fig. 9. Seven days. Dramatic increase in size and number of clusters, as well as in the pneumonic areas. The subsequent picture is one of very rapid extension of the disease processes, which continues unchecked until the onset of allergy.

(MS. received for publication 12. vIII. 59) 